\section{Letting go of inhibition}

\section{By Lev Osherovich, Senior Writer}

A University of California, San Francisco team has created a new class of reversible, covalent small molecule kinase inhibitors that could be more selective and safer than previous kinase inhibitors. ${ }^{1}$ Principia Biopharma Inc. has exclusively licensed the technology and plans to develop new compounds to treat cancer and autoimmune diseases.

Many first-generation kinase inhibitors hit multiple kinases in addition to the kinase implicated in disease, which often results in unwanted off-target effects.

One approach to producing next-generation kinase inhibitors with improved selectivity profiles has been to design compounds that irreversibly bind their target kinase and permanently inactivate it, which leads to fewer off-target effects and greater potency than using reversibly binding inhibitors. ${ }^{2}$

The most advanced examples of such irreversible, covalent inhibitors include two compounds that target Bruton's tyrosine kinase (Btk)-ibrutinib (PCI-32765) from Pharmacyclics Inc. and Johnson \& Johnson and AVL-292 from Celgene Corp.

Ibrutinib has completed Phase II testing in hematological malignancies. AVL-292 is in Phase Ib testing for B cell malignancies.

Although covalent, irreversible inhibitors show better selectivity than many first-generation kinase inhibitors, they still occasionally bind other kinases with structurally related cysteines, resulting in their permanent modification, corresponding author Jack Taunton told SciBX.

"No compound is completely selective," said Taunton. Covalent, irreversible inhibitors "may transiently concentrate in the liver and react irreversibly with other cysteine-containing proteins," potentially leading to toxicity after long-term use.

Taunton, a cofounder of Principia, was team leader and is associate professor of cellular and molecular pharmacology and pharmaceutical chemistry at UCSF and a Howard Hughes Medical Institute investigator.

Taunton's team set out to achieve the high potency of covalent inhibitors but with even lower off-target effects by designing a series of reversible, covalent inhibitors of ribosomal protein S6 kinase $90 \mathrm{kDa}$ polypeptide 3 (RPS6KA3; RSK2), which was used as a model kinase in the study.

The inhibitors consisted of two parts-a pyrrolopyrimidine group that blocked the kinase active site through noncovalent interactions and a reactive cyanoacrylamide group that formed a covalent bond with an exposed cysteine residue near the RPS6KA3 active site.
In a panel of 442 kinases, the best inhibitor bound RPS6KA3 with high affinity $\left(K_{\mathrm{d}}=540 \mathrm{pM}\right)$ and showed at least 400 -fold greater selectivity for RPS6KA3 than the other five closely related kinases, which bound loosely to the compound.

Moreover, the covalent bond that held the inhibitors in place was weaker than the bond formed by a control compound resembling Celgene's and Pharmacyclics' inhibitors. Indeed, in vitro kinase activity of RPS6KA3 inhibited by Taunton's compound could be restored by washing out the compound, suggesting that inhibition was reversible.

In cell culture, Taunton's best inhibitor was at least as effective at blocking RPS6KA3 activity and decreasing tumor cell invasiveness as an irreversible inhibitor.

The findings were reported in Nature Chemical Biology.

\section{Advantage needed}

Although the paper provided the rationale for designing covalent, reversible inhibitors of kinases, Principia plans to use the chemistry platform to develop inhibitors of a range of different enzymes in addition to kinases, said CEO Martin Babler.

Babler noted that any enzyme could be hit using Taunton's technology as long as it has an accessible cysteine near an inhibitor binding site.

"Our technology is not fundamentally focused on any therapeutic area but rather is focused on whether you have a cysteine in the protein that you want to target," said Babler. "With reversible, covalent technology you could go out of the field of kinase inhibition."

Babler said the company has lead compounds that hit RPS6KA3 and additional undisclosed targets in oncology and autoimmune disease. In February, Principia raised $\$ 12$ million in the first tranche of an expected $\$ 36$ million series A round. Investors were New Leaf
"Our technology is not fundamentally focused on any therapeutic area but rather is focused on whether you have a cysteine in the protein that you want to target. With reversible, covalent technology you could go out of the field of kinase inhibition."

- Martin Babler, Principia Biopharma Inc.

\section{Venture Partners, OrbiMed}

Advisors LLC, Morgenthaler Ventures, SR One and Mission Bay Capital.

Babler said that Taunton's approach offers an additional advantage over irreversible inhibitors-lower immunogenicity. He noted that as proteins wear out and are degraded by cellular garbage disposal systems, protein fragments modified by irreversible inhibitors are perceived by the immune system as foreign antigens, leading to inflammation and autoimmunity.

"One of the biggest concerns about irreversible compounds is the formation of immunogenic adducts. For this reason, people have been hesitant to take this technology into nononcology indications," said Babler. "The safety risk comes from the fact that the bond survives the 


\section{ANALYSIS}

denaturation and degradation of the protein. You get a molecule that the immune system recognizes as a foreign antigen."

In contrast, Taunton's team showed that its inhibitors readily fall off the kinase once it denatures and becomes inactivated, thereby avoiding the formation of an adduct that could trigger an immune response.

Taunton said his next step is to assess the in vivo safety and selectivity of his compounds. One way to do so would be to use whole-body radiolabeling studies to identify and quantify binding of reversible and irreversible inhibitors to off-target proteins.

Meanwhile, Taunton is collaborating with researchers at the University of Rochester to test the effects of his RPS6KA3 inhibitors in mouse models of metabolic disease.

The technology has been patented and is exclusively licensed to Principia.

Osherovich, L. SciBX 5(15); doi:10.1038/scibx.2012.382

Published online April 12, 2012

\section{REFERENCES}

1. Serafimova, I.M. et al. Nat. Chem. Biol.; published online April 1, 2012; doi:10.1038/nchembio.925

Contact: Jack Taunton, University of California, San Francisco, Calif.

e-mail: taunton@cmp.ucsf.edu

2. Flanagan, M. BioCentury 20(5), A7; Jan. 30, 2012

COMPANIES AND INSTITUTIONS MENTIONED

Celgene Corp. (NASDAQ:CELG), Summit, N.J.

Howard Hughes Medical Institute, Chevy Chase, Md.

Johnson \& Johnson (NYSE:JNJ), New Brunswick, N.J.

Mission Bay Capital, San Francisco, Calif.

Morgenthaler Ventures, Menlo Park, Calif.

New Leaf Venture Partners, New York, N.Y.

OrbiMed Advisors LLC, New York, N.Y.

Pharmacyclics Inc. (NASDAQ:PCYC), Sunnyvale, Calif.

Principia Biopharma Inc., South San Francisco, Calif.

SR One, Conshohocken, Pa.

University of California, San Francisco, Calif.

University of Rochester, Rochester, N.Y. 